Boise State University

ScholarWorks

Electrical and Computer Engineering Faculty

Department of Electrical and Computer

Publications and Presentations

Engineering

$1-1-2004$

\title{
Interaction Effects of Slurry Chemistry on Chemical Mechanical Planarization of Electroplated Copper
}

Peter A. Miranda

Boise State University

Jerome A. Imonigie

Boise State University

Amy J. Moll

Boise State University 


\title{
Interaction Effects of Slurry Chemistry on Chemical Mechanical Planarization of Electroplated Copper
}

\author{
P.A. Miranda, J. A. Imonigie, A.J. Moll \\ Department of Mechanical Engineering \\ Boise State University
}

\begin{abstract}
Recent studies have been conducted investigating the effects of slurry chemistry on the copper CMP process. Slurry $\mathrm{pH}$ and hydrogen peroxide concentration are two important variables that must be carefully formulated in order to achieve desired removal rates and uniformity. In applications such as throughwafer vertical interconnects, slurry chemistry effects must be thoroughly understood when copper plating thicknesses can measure up to 20 microns thick. The species of copper present on the surface of the wafer can be controlled through formulation of the slurry chemistry resulting in minimizing non-uniformity while aggressively removing copper. Using a design of experiments (DOE) approach, this study was performed investigating the interaction between the two variables during CMP. Using statistical analysis techniques, a better understanding of the interaction behavior between the two variables and the effect on removal rate and uniformity is achieved.
\end{abstract}

\section{INTRODUCTION}

Advancements made in integrated circuit (IC) fabrication have allowed new and innovative applications in microelectronics. One particular area of interest has been in the field of three-dimensional ICs. Building 3-D electronic devices will allow further miniaturization and enhance performance. Through-wafer interconnects (TWIs), combined with damascene architecture are the foundation of electrical connectivity in 3-D microchip structures. In this particular study, the research conducted was part of an effort to support the development of copper $(\mathrm{Cu})$ chemical-mechanical planarization (CMP) methods to be used on TWI applications. Initially, vias are created in silicon wafers with a Bosch etch process[1]. After the vias are formed, a polymer insulation coating, diffusion barrier and $\mathrm{Cu}$ seed are deposited on the surface of the wafer lining the wafer surface and via walls. Finally, a thick $\mathrm{Cu}$ layer is deposited by an electroplating process filling the vias and depositing a thick layer of copper across the wafer. The thick $\mathrm{Cu}$ layer is then removed by CMP leaving only the $\mathrm{Cu}$ in the vias intact. The electroplating process results in a non-uniform $\mathrm{Cu}$ plating layer 10-20 microns thick. The $\mathrm{Cu}$ plating thickness and non-uniformity stretch the capabilities of a conventional CMP process including consumables typically used in $\mathrm{Cu}$ CMP. Conventional CMP techniques are designed to planarize and remove metal layers that are typically 1-2 microns[2] thick, however, in TWI applications $\mathrm{Cu}$ plating layers are much thicker.

Although the $\mathrm{Cu}$ CMP process has been well documented, limited information regarding CMP of TWIs is available. As with any CMP process, slurry chemistry and machine parameters are paramount in obtaining desired removal rates and uniformity. Slurries used in the CMP process provide the chemical and mechanical mechanisms needed for material removal. In $\mathrm{Cu} \mathrm{CMP}$, abrasive particles such as alumina or colloidal silica are suspended in the slurry and aid in mechanical removal while slurry $\mathrm{pH}$ and hydrogen peroxide $\left(\mathrm{H}_{2} \mathrm{O}_{2}\right)$ provide the chemical reactions needed to facilitate the removal of $\mathrm{Cu}$. Although extensive research has been conducted investigating the effects of slurry $\mathrm{pH}$ and $\mathrm{H}_{2} \mathrm{O}_{2}$ during CMP [3-5], limited work has been done exploring the interaction effects between the two variables when dealing with thick $\mathrm{Cu}$ layers. The effect of slurry $\mathrm{pH}$ and complexing agents such as EDTA, citric acid and glycine on $\mathrm{Cu}$ removal rates has been well documented[4]. However, information relating the effect of slurry $\mathrm{pH}$ and peroxide concentrations on $\mathrm{Cu}$ removal rates is limited to $\mathrm{Cu}$ thickness of 1-2 microns.

In $\mathrm{Cu} \mathrm{CMP}$ applications, $\mathrm{H}_{2} \mathrm{O}_{2}$ is used as the oxidizing agent and is added to the slurry prior to use. $\mathrm{H}_{2} \mathrm{O}_{2}$ reacts with the $\mathrm{Cu}$ surface and aids in the formation of a thin passivation layer of copper (II) oxide $(\mathrm{CuO})$ or copper $(\mathrm{I})$ oxide $\left(\mathrm{Cu}_{2} \mathrm{O}\right)$, depending on the $\mathrm{H}_{2} \mathrm{O}_{2}$ concentration used. The process is repeated until the $\mathrm{Cu}$ plating layer has been planarized and removed. Recommended $\mathrm{H}_{2} \mathrm{O}_{2}$ concentrations vary depending on the slurry manufacturer and can range from $1.5 \%$ to $5 \%$ by volume.

Slurry $\mathrm{pH}$ also plays a significant role in $\mathrm{Cu} \mathrm{CMP}$ and can be formulated to be either basic or acidic depending on the manufacturer. As mentioned earlier, slurry $\mathrm{pH}$ and the concentration levels of $\mathrm{H}_{2} \mathrm{O}_{2}$ have been found to result in the formation of a hard passivation layer of $\mathrm{CuO}$ or $\mathrm{Cu}_{2} \mathrm{O}$ on the surface of the $\mathrm{Cu}[4,5]$. In general, and in accordance with the $\mathrm{Cu}$ Pourbaix diagram[6], a number of studies have shown that surface chemistry in the basic region combined with a given peroxide concentration, can lead to the formation of $\mathrm{CuO}$. Conversely, with slurry $\mathrm{pH}$ in the acidic region, hydrogen ion concentrations $\left[\mathrm{H}^{+}\right]$are increased resulting in the formation of $\mathrm{Cu}^{2+}$ whereas the formation of $\mathrm{CuO}$ is not thermodynamically favorable.

For this study, slurry pH levels of 4 and 8 were chosen representing the regions in the $\mathrm{Cu}$ Pourbaix diagram where $\mathrm{Cu}$ can exist as $\mathrm{Cu}^{2+}$ and $\mathrm{CuO} / \mathrm{Cu}_{2} \mathrm{O}$, respectively. Surface 
chemistry of the $\mathrm{Cu}$ plating layer can be controlled by slurry $\mathrm{pH}$ and $\mathrm{H}_{2} \mathrm{O}_{2}$ concentration. By generating the ideal $\mathrm{Cu}$ species on the surface of the wafer, desired removal rates and uniformity can be achieved. The goal of this study was to use a design of experiments (DOE) approach to systematically investigate and learn the important interactions of $\mathrm{pH}$ and peroxide concentrations on the removal rate of $\mathrm{Cu}$ and withinwafer-non-uniformity (WIWNU).

\section{MATERIALS AND EXPERIMENTAL METHODS}

The slurry used throughout the experiment was Cabot 5001 . The slurry contains alumina based abrasives and is batch processed to a $\mathrm{pH}$ of $\sim 8$. The slurry is formulated to remove $\mathrm{Cu}$ at a rate of up to 1.0 micron per minute under typical machine conditions. Each slurry batch was prepared prior to each experiment with nitric acid added to obtain the desired $\mathrm{pH}$ level. To eliminate problems with slurry deterioration between repeated conditions, a new batch of slurry was mixed prior to each run.

The type of pad used was a Cabot EPAD-A100 CMP polishing pad. Prior to beginning the experiment, the pad was conditioned, ex-situ, using a Morgan Advanced Ceramics Diamone ${ }^{\mathrm{TM}}$ pad conditioner. In addition, single conditioning routines were performed between each run to ensure pad consistency during the experiment.

The experiments were performed on a Strasbaugh 6DS-SP Planarizer using a standard wafer carrier. Machine parameters such as down force, table speed and spindle speed were held constant throughout the experiment to ensure data collection consistency. Listed in Table 1 are the machine parameters used during the experiment.

To investigate the effects of slurry $\mathrm{pH}$ and $\mathrm{H}_{2} \mathrm{O}_{2}$ on the CMP process, a design of experiment (DOE) approach was used. By using a DOE approach, a systematic method to perform experiments investigating slurry $\mathrm{pH}$ and $\mathrm{H}_{2} \mathrm{O}_{2}$ interactions could be performed. Any significant effects or interactions dominant during the CMP process could be properly identified. The DOE structure used was a $2^{2}$ full factorial experiment with three replicates for a total of 12 runs. Table 2 contains the factors and respective levels used in the DOE.

$\mathrm{Cu}$ removal rates and the change in WIWNU were chosen as the response variables. After the factors and response variables were determined, the data was entered into the DOE software JMP[7], which generated the experimental matrix and run order.

Table 1. Machine parameter settings used throughout the experiment

\begin{tabular}{|c|c|}
\hline \multicolumn{2}{|c|}{ Machine Parameters } \\
\hline Down Force(psi) & 4 \\
\hline Table Speed(rpm) & 60 \\
\hline Spindle Speed(rpm) & 60 \\
\hline Slurry Flow Rate(ml/min) & 200 \\
\hline Time(sec) & 60 \\
\hline
\end{tabular}

Table 2. Factors and levels used in factorial experiment

\begin{tabular}{|c|c|c|}
\hline & \multicolumn{2}{|c|}{ LEVEL } \\
FACTOR & Low & High \\
\hline Slurry pH & 4.0 & 8.0 \\
\hline$\% \mathrm{H}_{2} \mathrm{O}_{2}$ & 1.5 & 3.5 \\
\hline
\end{tabular}

As-received slurry $\mathrm{pH}$ and $\mathrm{H}_{2} \mathrm{O}_{2}$ concentrations amounts were used based on supplier specifications. Each experimental condition was run three times in random order in an attempt to normally distribute any unknown sources of error about zero. $\mathrm{Cu}$ removal rates were determined from the change in $\mathrm{Cu}$ thickness after each run as measured by an Automatic Four Point Probe (AFPP). To calculate the change in WIWNU, the sample standard deviation from each measurement set was divided by the sample mean and used as the percentage of nonuniformity across the wafer.

The experiments were performed with four-inch diameter wafers electro-plated with approximately 0.5 microns to 2 microns of $\mathrm{Cu}$. Incoming plating thickness and uniformity varied across all wafers used in the experiment and may have contributed to variation experienced in repeated runs.

\section{RESULTS}

After completing the experiment, the data was entered into the DOE software and analyzed. Table 3 contains the average results of both removal rate and WIWNU. Using analysis of variance (ANOVA), both factors and levels were analyzed to determine if any single variable or combination had any statistical significance on removal rate and WIWNU.

\section{A. Removal Rate}

Slurry $\mathrm{pH}$ and the interaction between $\mathrm{pH}$ and $\mathrm{H}_{2} \mathrm{O}_{2}$ concentration were the main contributors to removal rate based on p-values of 0.0021 and 0.0207 , respectively. With a p-value of 0.588 , the concentration of $\mathrm{H}_{2} \mathrm{O}_{2}$ alone, did not indicate any significance to the model and was rejected as having any significance.

Table 3. Average results of removal rate and WIWNU. Negative WIWNU results indicate an increase in non-uniformity.

\begin{tabular}{|c|c|c|}
\hline $\begin{array}{c}\text { Factors } \\
\text { and Levels }\end{array}$ & $\begin{array}{c}\text { Average Removal } \\
\text { Rate (Ang/min) }\end{array}$ & $\begin{array}{c}\text { Average } \\
\text { WIWNU (\%) }\end{array}$ \\
\hline $\begin{array}{c}\mathrm{pH}-\mathrm{High} \\
\% \mathrm{H}_{2} \mathrm{O}_{2}- \\
\mathrm{High}\end{array}$ & 243 & 4 \\
\hline $\begin{array}{c}\mathrm{pH}-\mathrm{High} \\
\% \mathrm{H}_{2} \mathrm{O}_{2}- \\
\mathrm{Low}\end{array}$ & 1743 & -32 \\
\hline $\begin{array}{c}\mathrm{pH}-\mathrm{Low} \\
\% \mathrm{H}_{2} \mathrm{O}_{2}- \\
\mathrm{High}\end{array}$ & 2908 & -38 \\
\hline $\begin{array}{c}\mathrm{pH}-\mathrm{Low} \\
\% \mathrm{H}_{2} \mathrm{O}_{2}- \\
\mathrm{Low}\end{array}$ & 1953 & -12 \\
\hline
\end{tabular}


The model adequacy was checked by reviewing the adjusted- $\mathrm{R}^{2}$ value of 0.69 which did prove to be adequate, although higher values are desired to account for variability in the model.

Interaction between slurry $\mathrm{pH}$ and $\mathrm{H}_{2} \mathrm{O}_{2}$, were shown to have a significant impact on $\mathrm{Cu}$ removal as seen in Figure 1. Slurry $\mathrm{pH}$ had the greatest impact on removal rate when combined with a high level of $\mathrm{H}_{2} \mathrm{O}_{2}$ concentration. Conversely, at low concentration levels of $\mathrm{H}_{2} \mathrm{O}_{2}$, changes in slurry $\mathrm{pH}$ did not have a significant impact on removal rate. The decrease in the removal rate at high $\mathrm{pH}$ and high concentrations of $\mathrm{H}_{2} \mathrm{O}_{2}$ may be explained in terms of the formation of $\mathrm{CuO}$, which impedes the removal of $\mathrm{Cu}$. In contrast, the increase in removal rate at low $\mathrm{pH}$ and high levels of $\mathrm{H}_{2} \mathrm{O}_{2}$ concentration may be explained by the formation of $\mathrm{Cu}^{2+}$ ion which is easier to remove during CMP. Insignificant differences with low levels of $\mathrm{H}_{2} \mathrm{O}_{2}$ concentration at both $\mathrm{pH}$ levels may also be explained by the formation of $\mathrm{Cu}_{2} \mathrm{O}$ at high $\mathrm{pH}$ which is preferred for CMP compared to the $\mathrm{CuO}$. This line of argument is supported by the report of Wei et al.[5] who observed and measured the formation of $\mathrm{Cu}_{2} \mathrm{O}$ with the addition of $0.06 \% \mathrm{H}_{2} \mathrm{O}_{2}$ and the formation of $\mathrm{CuO}$ with the addition of $2.5 \% \mathrm{H}_{2} \mathrm{O}_{2}$ at a slurry $\mathrm{pH}$ of 8 .

\section{B. Within-wafer-non-uniformity}

In analyzing the WIWNU data, the normal probability plot revealed problems with constant variance. Based on the lack of constant variance, a transformation of the data was needed to stabilize the variance distribution and obtain a suitable model. The adjusted- $\mathrm{R}^{2}$ value also contained issues with model adequacy as did the residual versus predicted plot. Using the Box-Cox method to obtain an appropriate model, a log transformation was chosen to eliminate problems with variation and develop a suitable model to interpret the data. After transformation, the WIWNU data was re-analyzed and did provide information regarding significant factor contributions. Slurry $\mathrm{pH}, \mathrm{H}_{2} \mathrm{O}_{2}$ concentration and the interaction between the two variables did have an impact on WIWNU.

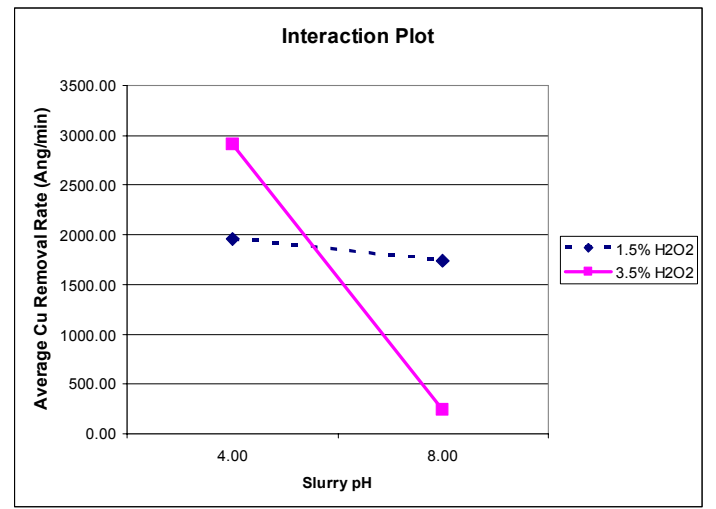

Figure 1. Interaction plot of $\mathrm{Cu}$ removal rate between slurry $\mathrm{pH}$ and $\mathrm{H}_{2} \mathrm{O}_{2}$ concentration.

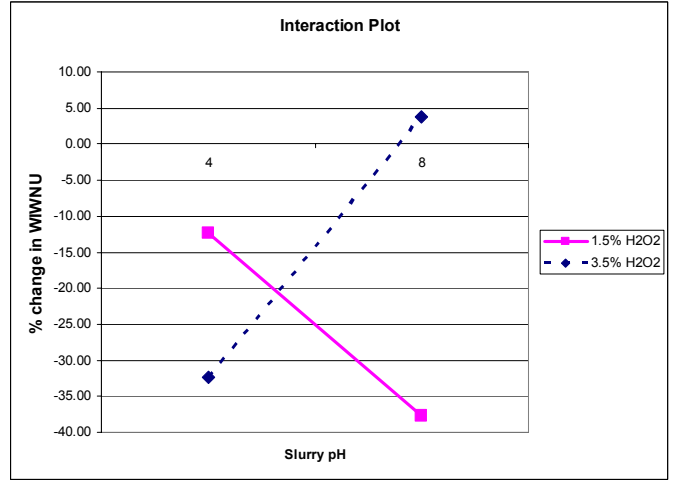

Figure 2. Interaction plot of average percent change in WIWNU between slurry $\mathrm{pH}$ and $\mathrm{H}_{2} \mathrm{O}_{2}$ concentration.

However, with a p-value of 0.93 , slurry $\mathrm{pH}$ did not have a significant effect as compared to $\mathrm{H}_{2} \mathrm{O}_{2}$ concentration and the interaction between slurry $\mathrm{pH}$ and $\mathrm{H}_{2} \mathrm{O}_{2}$ concentration. Although the results obtained do require extra caution in interpretation due to the transformation performed of the data, the ANOVA did reinforce the significance of the two factors. In reviewing the interaction plots, both high and low levels of $\mathrm{H}_{2} \mathrm{O}_{2}$ concentration did result in a significant change in WIWNU based on slurry $\mathrm{pH}$ levels.

\section{CONCLUSIONS}

In conclusion, the analysis did reveal insight into the interaction effects occurring during $\mathrm{Cu} \mathrm{CMP}$ between two very common slurry chemistry variables. Changes in slurry $\mathrm{pH}$ had the greatest impact on the process when $\mathrm{H}_{2} \mathrm{O}_{2}$ content was at the high level of $3.5 \%$. At $3.5 \% \mathrm{H}_{2} \mathrm{O}_{2}$ and a slurry $\mathrm{pH}$ of 4 , high $\mathrm{Cu}$ removal rates were achieved. In contrast, the lowest changes in WIWNU occurred at low concentrations of $\mathrm{H}_{2} \mathrm{O}_{2}$ and a $\mathrm{pH}$ of 8 . This combination also accounted for smaller levels in $\mathrm{Cu}$ removal.

Based on $\mathrm{Cu}$ Pourbaix diagrams, the type of species generated on the surface of the $\mathrm{Cu}$ is important in achieving desired removal rates and WIWNU. In the basic region, the $\mathrm{Cu}$ species formed will impede the oxidation process due to formation of the $\mathrm{CuO}$ layer. In the acidic region, $\mathrm{Cu}^{2+}$ ion is formed which is easily removed during the CMP process creating an aggressive condition to increase removal rate and WIWNU.

With the goal of $\mathrm{Cu} \mathrm{CMP}$ to be high removal rates while maintaining uniformity, a compromise between both response variables will need to be addressed in order to achieve an optimum process condition. The experiments performed in this study show the impact of surface chemistry in trying to achieve desired removal rates and WIWNU when dealing with thick $\mathrm{Cu}$ plating, however, further studies would be required to investigate noise effects contributed by wafer-to-wafer plating variation.

Based on the data collected by this experiment, future efforts will be focused on the development of optimized process conditions for thick $\mathrm{Cu}$ removal of TWIs. Research in 
the area of $\mathrm{Cu}$ removal as related to dishing and erosion of TWIs will also be investigated.

\section{ACKNOWLEDGEMENTS}

This project is supported by the DARPA MTO office and administered by SPAWAR SYSCEN/San Diego, CA under Grant N66001-00-1-8950. Special thanks to Micron Technology, Cabot Microelectronics and Morgan Advanced Ceramics for their continued support.

\section{REFERENCES}

1. Craigie, C.J.D., et al., Polymer thickness effects on Bosch etch profiles. Journal of Vacuum Science and Technology B: Microelectronics and Nanometer Structures, 2002. 20(6): p. 2229-2232.

2. Li, S., et al., A Low Cost and Residue-Free AbrasiveFree Copper CMP Process With Low Dishing,
Erosion And Oxide Loss. 2001, CMP Business Group, Applied Materials.

3. Hernandez, J., P. Wrschka, and G.S. Oehrlein, Surface Chemistry Studies of Copper Chemical Mechanical Planarization. Journal of The Electrochemical Society, 2001. 148(7): p. 389-397.

4. Jindal, A., Y. Li, and S.V. Babu, Effect Of pH On Chemical Mechanical Polishing Of Copper And Tantalum. Mat. Res. Soc. Symp. Proc., 2001. 671.

5. Wei, D., et al., Copper CMP for Dual Damascene Technology: Some Considerations on the Mechanism of Cu Removal. Mat. Res. Soc. Symp. Proc., 2001. 671: p. 1-7.

6. Pourbaix, M., Atlas of Electrochemical Equilibria in Aqueous Solutions. 1966, New York: Pergamon Press. 384.

7. Sall, J., Design of Experiments, in JMP. 2002: Cary, NC. 